\title{
¿COMPAÑERO DE RUTA?
}

\author{
Horacio Cerutti-Guldberg
}

Universidad Nacional Autónoma de México

DOI:10.14718/CulturaLatinoam.2017.26.2.10

Lo único que existe es la memoria que pasa por la razón y que pasa por el corazón, porque el olvido no existe. BEATRIZ TORRES (2014)

Aunque nuestras vidas han tenido trayectorias muy diversas, siempre nos hemos sentido cercanos y en relación muy fraterna. Con orígenes geográficamente distantes -nacido uno en Cuba y el otro en Argentina-, eso no solo no nos ha apartado sino que, por el contrario, nos ha acercado más. ¿Cuándo y cómo nos conocimos? No lo recordamos con precisión. O nos resistimos a recordarlo, quizá porque parece que hubiera sido una relación fraterna de toda la vida. Maestros y maestras, amigos y amigas en común, preocupaciones compartidas, anhelos convergentes, esfuerzos tenaces. Dos estilos muy específicos, aunque con rasgos nodales claramente identificables. Compañeros de búsquedas incansables.

Nos hubiera gustado entrar en múltiples detalles de la producción filosófica y, más ampliamente, intelectual de Pablo Guadarrama, pero dificultades personales ineludibles nos han impedido hacerlo. A pesar de tan difíciles momentos, no podemos estar fuera de este merecidísimo

1. Responsable General del Centro Académico de la Memoria de Nuestra América, UACM, México, D. F., palabras pronunciadas en un evento realizado en 2014, recordando la visita en 2009 de Noam Chomsky.

Referencia: Cerutti-Guldberg, H. (2017). ¿Compañero de ruta? Cultura Latinoamericana. Revista de Estudios Interculturales. 26(2), pp. 239-250. DOI:10.14718/CulturaLatinoam.2017.26.2.10 
homenaje y, por lo tanto, hemos optado por una estrategia menos académica y más experiencial, aunque no por eso -al menos es la pretensión, esperamos que no desmesurada-poco pertinente o con falta de rigor informativo y argumental.

No sabemos quién tenga más ejemplares de publicaciones del homenajeado que nosotros. No poder detenernos a releer y leer como es nuestro hábito nos coloca en una posición de tensión inmensa. Con todo, intentaremos aportar algo al debate compartido, sobre todo después de haber visto muy por encima algunas de las magníficas contribuciones a este reconocimiento.

El estilo del cubano homenajeado tiene caracteres marcados y acendrados en su amplia producción. Tiende a la erudición, pero no en sentido pedante, sino como ingrediente ineludible de panoramas que requieren ser construidos, reconstruidos o, al menos, aludidos de modo coherente e intenso. No se solaza en la pretensiosa petulancia terminológica o en los juegos de neologismos, sino que asume los retos de frente y sin evasiones seudo 'diplomáticas'. Dice lo que considera adecuado, pertinente, correcto y no duda en compartir aquello en que cree. No elude referencias a las dificultades epistémicas y metodológicas con que se topa e intenta procurar resolverlas del modo más adecuado. No tiembla ante los riesgos de un filosofar propio y responsable. Busca, lee, indaga, husmea, y no pierde ocasión de estar muy alerta frente a los desafíos que enfrentamos. No considera fecundo ignorar legados y tradiciones, antecedentes y valiosos aportes o desatinos de esfuerzos que nos han precedido. Le entra al diálogo y a la interlocución, sin juicios ad hominem y, mucho menos, descalificaciones previas. Todo lo disponible admite y requiere ser reconstruido y examinado en profundidad y con rigor. La ironía y el humor andan siempre allí, junto a un esfuerzo obstinado por encontrar expresiones y narrativas que permitan hacer accesible a las y los demás lo que él está elucubrando. Así nos aventuramos a advertir riesgos, compartir perspectivas, examinar propuestas, esclarecer equívocos, procurar avanzar hacia lo que se ansía construir.

Retomando estos puntos compartidos, quizá el aspecto que algo nos distancia es la dimensión erudita. Aunque en nuestro caso no la eludimos, no es frecuente -quizá es pura ingenuidad en nuestra misma autoapreciación y relecturas- advertirla en nuestros textos. También la nuestra es una retórica muy escueta; preferible cuanto más concisa. Frente a su elocuencia, tendemos a ser muy parcos... Pero, salvando nuestras limitaciones, seguimos juntos en el compromiso y las tareas responsables. 
¿Tienen relevancia estos esfuerzos actualmente? Pensar en la coyuntura, siempre es así, pero hay quienes logran salirse de esa malla absorbente y se lanzan a volar por quién sabe dónde. No es el caso. Y percibimos ambos, claramente, ¡cuánta labor queda por hacer!

Nos conviene enumerar algunos tópicos compartidos ante los que permanecemos muy atentos: identidad, modernidad, cultura, humanismo, historia, política, ética, estética, educación, pedagogía, valores, revolución, reformas, clases y lucha de clases, «tercera posición», etc.

En una presentación biográfica muy bien elaborada, dos colegas cubanos lo ubican finalmente del siguiente modo: «En general el filósofo cubano, evitando asumir posiciones neoortodoxas, se reconoce dentro de una postura realista crítica» (León del Río \& Valdés García, 2001, p. 115).

Este realismo crítico, por supuesto, tiene antecedentes y viene marcado, si así cabe decirlo, por el marxismo, especialmente en versión marxista-leninista, al tiempo que procura ser lo más realista y crítico que se pueda lograr. Quizá el mejor modo de reconocerse en esa tradición marxista lo logra Pablo siguiendo lo que señalaba el español transterrado en México, Wenceslao Roces en una interesante entrevista que le realizara Gabriel Vargas Lozano:

El marxista que no es más que marxista, que no sabe más que marxismo, no es un marxista ni sabe nada de nada. El marxismo tiene que interesarse por todo, abrirse a todo [...] El marxismo es un instrumento de trabajo no un distintivo para colgárselo en la solapa... (citado por Guadarrama, 1990, p. 59).

Queda claro: lo que andamos buscando es un buen instrumento para las transformaciones en curso, en las que venimos trabajando y de las cuales participamos plenamente. Así lo reconocía Pablo (1979):

El marxismo-leninismo es una concepción del mundo que posee un valioso método: el dialéctico materialista, él nos permite valorar en su condicionamiento histórico social cada etapa de la historia de la filosofía (p. 176).

Junto con otro colega se enfrentaba también a ciertas versiones de la historiografía filosófica cubana, las cuales encubrían «[...] obviándose o silenciándose la pugna materialismo versus idealismo como la ley fundamental en el movimiento del pensamiento filosófico» (p. 176).

Esta dimensión de la legalidad aparece, reaparece y se mantiene, hasta donde alcanzamos a percibir, en el pensamiento de Pablo. Pero, eso no significa, de ninguna manera, que él proponga devalorizar o 
minusvalorar la producción filosófica cubana y de la región. Es más, no ha dudado Pablo en enfrentarse a quienes pretenden descalificar esas expresiones producidas en nuestra región, usando la comparación con lo literario de modo despreciativo, cuando afirmaba tajantemente: «[...] son falsos los criterios de algunos historiadores respecto al carácter meramente literario de la expresión filosófica cubana o latinoamericana de esa época [...]» (Guadarrama, 1979, p. 419). Y de cualquier época, nos permitiríamos añadir. Para el caso de Nuestra América la cuestión tiene incluso aristas valiosísimas, imposibles de descuidar (y, menos, de examinar aquí exhaustivamente, como sería deseable). A propósito de la literatura, Armando Hart Dávalos (2008) decía en el «Prólogo a la edición cubana de 2001» de un libro de Pablo (lo retomamos de la edición venezolana):

Estamos en el deber de hacer en Filosofía, en el siglo xxI, lo que se hizo a principios del siglo xx en la Literatura, es decir, asumir el legado intelectual europeo, renovarlo y actualizarlo y procurar, con originalidad, que resulte eficaz para encontrar nuevos caminos para Nuestra América (p. 23).

Lo anterior implica reconocer la creatividad de nuestra literatura y advertir que, incluso, tiene aportes imperdibles a nuestro filosofar.

En otros trabajos anteriores resaltaría Pablo las dimensiones de la filosofía, la cual se hace seriamente accesible gracias a los enfoques de Marx y Engels:

Con el descubrimiento de que son los hombres los que hacen la historia, pero de acuerdo a [sic] determinadas condiciones materiales objetivas independientes de su voluntad es que se abre la posibilidad real del estudio científico de la historia de la filosofía (Guadarrama, 1979, p. 163).

Salta a la vista que aquí cabría interrogarnos: ¿y para qué estudiar la historia de la filosofía? La respuesta de Pablo tampoco se anda por las ramas: «Sencillamente porque no existe la posibilidad de la arrancada a partir de cero» (Guadarrama, 1994, p. 105).

Y Pablo tiene muy presente que una de las modalidades, quizá la más fecunda, que adoptó la historia de la filosofía entre nosotros fue la historia de las ideas (siempre filosóficas). Esto no implica que efectúe aportes indiscutibles ni mucho menos. Todo está a merced de la crítica rigurosa y pertinente. Al respecto, el colega y amigo brasileño Eugênio Rezende de Carvalho (2009) brinda una visión de conjunto sugerente en uno de sus múltiples trabajos dedicados 
al tema y precisa con todo cuidado las metamorfosis epistémicas que se producen, para no quedar acotados a una «historiografía» meramente reconstructiva: «Em tal deslocamento epistemológico, as funcoes da história das ideias seriam alargadas de forma a extrapolar a mera dimensao historiográfica propiamente dita, abarcando as esferas ideológicas, especulativas e teleológicas» (p. 108).

Pablo Guadarrama (1985) se dedicará, en este marco, al examen y crítica del humanismo burgués producido en nuestra región, proporcionando sugerencias y perspectivas sumamente relevantes. Con perspicacia, advierte:

[...] una vez que esta clase [la burguesía] establece su dominio, abandona cada vez más la propia tradición humanista que le inspiró y encubre en un manto de abstracciones irrealizables las aspiraciones de las masas populares que hicieron posible su victoria (p. 147).

El humanismo burgués en la región anduvo siempre buscando una supuesta «tercera posición» entre capitalismo y socialismo. Esto lo señala siempre Pablo. «Fueron muy comunes los intentos por encontrar una "tercera vía" que evadiera los partidos filosóficos fundamentales, es decir, el del idealismo y el materialismo [...]» (Guadarrama \& Rojas, 1995, p. 421).

Los filósofos latinoamericanistas, adherentes a la supuesta «tercera posición», quedan así muy desprovistos de sólidos elementos argumentales.

Las anteriores pretensiones de los filósofos latinoamericanos de gestar un humanismo por encima del individualismo y el colectivismo, del capitalismo y el socialismo son cada vez más raras, porque el desarrollo histórico ha demostrado las funestas consecuencias que ha traído para la América Latina la dominación imperialista norteamericana y simultáneamente ha revelado la falsedad de las campañas anticomunistas (Guadarrama, 1985, p. 166).

Como es habitual en sus reflexiones, no pretendía Pablo descalificar sin más estas propuestas. Buscaba llamar la atención sobre las limitaciones de las mismas y no le tembló la mano ante la crítica que le merecieron destacados autores. Lo que procuraba era mostrar cómo esas propuestas aparecían ya completamente descontextualizadas y a destiempo.

El humanismo burgués ha tenido en América Latina prestigiosos representantes que en determinadas circunstancias históricas han desempeñado 
una función progresista. Tanto su labor filosófica como su actividad orientada a la consecución de su ideal humanista deben merecer el reconocimiento debido. Pero la hora del humanismo burgués ha pasado ya [...] (Guadarrama, 1985, p. 166).

Aquí conviene preguntarnos si de veras será así. No en el sentido en que lo plantea Pablo, el cual compartimos plenamente, sino en cuanto a su utilización más manipuladora... por parte de lo que el mismo Pablo denominara, a nuestro juicio con gran precisión: «burguesía nacional frustrada» (Guadarrama, 1983, p. 126).

Todo este debate y la producción misma de ideas transcurren en un proceso histórico que es, al mismo tiempo, cultural. Y allí se imponen riesgosas $-\mathrm{y}$ hasta inconscientes- acciones como la de la pretendida «sustitución de culturas»:

Esta forma de sustitutismo establece un abismo entre el pasado y el futuro, y no se percata de la imposibilidad de concebir proyectos que no presupongan una realidad dada ya que toda nueva cualidad [sic] encierra en su ser los elementos superados y siempre presentes de la anterior (Guadarrama, 1983, p. 129).

Aquí la labor de reflexión deja de ser responsable y asumida protagónicamente para convertirse en mera reiteración deformante.

Esta receta misantrópica, emparentada, en definitiva con el hegemonismo que analizamos anteriormente revela el estado de desesperación en que se encuentran algunos sectores de los intelectuales burgueses, que no pueden ver con despejado optimismo el futuro y tratan de imponer la originalidad de la filosofía latinoamericana a través de filosofías que ya no son nada originales y que han demostrado incluso su total ineficacia práctica con la derrota del fascismo y que siempre estarán condenadas al fracaso porque se oponen al amor que sienten todos los pueblos del mundo por la paz y la democracia. Las filosofías de la fuerza se verán siempre refutadas por la fuerza de la filosofía [...] (Guadarrama, 1983, p. 132).

Muchas propuestas de lo conocido como filosofía latinoamericana son puestas en el ojo del huracán por Pablo y va mostrando con mucho rigor sus falencias y debilidades tanto epistémicas como ideológico-políticas. Lo cual no es cualquier detalle y, muchísimo menos, son atribuciones impertinentes. 
También en el texto conjunto con Pereliguin (1988) surge la noción de pueblos «encubiertos» en aquellos momentos en que se discutía si era descubrimiento, encuentro, choque, encontronazo con motivo de los supuestos 200 años...

La negación de la existencia de leyes del desarrollo del pensamiento filosófico conduce frecuentemente a los historiadores burgueses de la filosofía a no aceptar la existencia de un camino progresivo, ascendente de esta forma de la conciencia social (Guadarrama, 1979, p. 130).

Esta linealidad suele ir asociada a una visión de la filosofía como completamente «inútil».

Una de las formas en que la historiografía burguesa contemporánea de la filosofía tergiversa la verdad consiste en considerar la filosofía como una actividad inútil, sin sentido práctico, como algo totalmente desvinculado de las necesidades reales de la sociedad (Guadarrama, 1979, p. 175).

Este esfuerzo historiográfico resulta importante para saber dónde estamos y cómo podemos avanzar. Aunque conviene revisar la negación de existencia de filosofía previa a la llegada de ibéricos y su «reducción» a pura mitología... Especialmente cuando advertimos que las articulaciones entre mito y logos son intrínsecas (temática que no podemos desarrollar aquí).

En estos días en que todavía está fresca la pérdida de un Gabo que siempre seguirá brindando sus aportes, resalta que en varias ocasiones se remitiera a él para esclarecer la noción de cultura.

No sin falta de razón Gabriel García Márquez ha sostenido que «cuando se habla de cultura, la dificultad principal reside en que esta carece de definición. Para la Unesco, la cultura es lo que el hombre agrega a la naturaleza. Todo lo que es producto del ser humano. Para mí, la cultura es el aprovechamiento social de la inteligencia humana. En el fondo, todos sabemos qué abarca el término cultura, pero no podemos expresarlo en dos palabras» (Colectivo de autores, 2009, p. 146)².

En otro trabajo, remitiendo a la misma referencia, insistiría en que: «La cultura puede considerarse como el aprovechamiento social de

2. Cursivas en el original. De este colectivo de autores participó Pablo. El mismo fragmento aparece citado por Pablo (2002) en su ponencia «El tema de la cultura en el pensamiento latinoamericano» ( p. 102). 
la inteligencia humana, dice Gabriel García Márquez» (Guadarrama, 2008, p. 141).

Años antes habían señalado, recuperando aspectos de la propuesta de Babosov (citado por Guadarrama \& Pereliguin, 1988):

Es posible que una de las formulaciones menos confusas que puedan ofrecerse sobre la cultura sea aquella que considera a esta categoría como la destinada a revelar la medida en que el hombre domina las condiciones de su existencia en formas histórico-concretas (p. 46).

Este afán por precisar de qué hablamos cuando nos referimos a cultura o a algo culto es casi constante en su obra.

Sólo una acción libre en la sociedad -cualesquiera que sean los parámetros que la circunscriban-, que parta del presupuesto del conocimiento y dominio de sus posibles repercusiones, debe ser considerada propiamente culta (Guadarrama, 2008, p. 141).

Y en este mismo artículo comparte unas precisiones que resultan imperdibles para el esfuerzo colectivo:

Una posible definición integradora debe considerarla como el grado de dominación por el hombre de las condiciones de vida de su ser, de su modo histórico concreto de existencia, lo cual implica de igual modo el control sobre su conciencia y toda su actividad espiritual, posibilitándole mayor grado de libertad y beneficio a su comunidad [...] No es paradójico afirmar que la cultura salvará al mundo, si el mundo sabe salvar a la cultura (Guadarrama, 2008, p. 141).

Entonces, no solo no conviene desatender a dimensiones culturales -siempre enraizadas junto a otras como económicas, políticas, etc.-, sino que no queda más que enfrentar con toda precisión dislates y «moditas» destinadas a desvirtuar búsquedas y a desacreditar esfuerzos. Esto, como siempre, no es equivalente a ignorar o minimizar aportes. Un caso específico, que conviene destacar porque la reacción de Pablo fue casi inmediata, remite al postmodernismo. Hay que atender a sus reflexiones, porque tienen una carga de vigencia muy fecunda. Por ejemplo, cuando se preguntaba:

[...] ¿de qué nos viene a rescatar el postmodernismo? Y después ¿qué propone en sustitución de lo derruido? [...] renuncia de hecho a la posi- 
bilidad de una reorientación de la historia humana, porque no admite ni tendencias en ella, ni que el hombre actúe conscientemente para lograr su perfeccionamiento, porque ni siquiera admite la existencia de tal proceso, entonces es preferible continuar completando nuestra imperfecta modernidad (Guadarrama, 1994, p. 109).

¿Cómo colocarnos ante esta sensibilidad pretensiosa? Así lo decía y hacía Pablo en su momento:

Ante la avalancha cultural del postmodernismo sólo es posible una actitud consecuente: asimilar dialécticamente sus críticas a las insuficiencias y descalabros de la modernidad [...] También debemos asumir una actitud renovadora, moderna ante el postmodernismo (Guadarrama, 1994, p. 110) ${ }^{3}$.

No sin ironía, culminaba una ponencia con esta «sugerencia»:

La desalienación humana ha logrado conquistas muy significativas durante la modernidad, y las actuales generaciones tienen el deber de reconocerlas para sentirse más libres y actuar en correspondencia con esos mayores grados de libertad, pero parece ser que definitivamente esta tarea ha sido traspasada a la postmodernidad (Guadarrama, 1995, p. 1096).

Dicha perspectiva no permite dejar de insistir en lo que tiene de valioso la dimensión moderna ante lo que se enfrenta la humanidad en estos momentos.

Obcecadamente cabe propiciar la reflexión filosófica. Filosofar es parte de nuestro quehacer. Según Pablo, «La filosofía le concede al hombre lo que la religión le niega: la comprensión de sus capacidades...» (Guadarrama, 1983, p. 120). Comprender estas capacidades y asumirlas es el modo de enfrentar «soluciones» que dejan en manos de algo inefable lo que nos corresponde hacer. Por ello su metáfora de «pensar con cabeza propia» nos resulta tan fecunda. Sus términos incentivan al máximo. Leámoslo:

En cualquier circunstancia es recomendable pensar con cabeza propia. Pero en algunas ocasiones es más necesario que en otras [...] Pensar con cabeza propia no significa asumir posturas de chovinismo epistémico y cerrarse a los aportes del pensamiento provenientes de cualquier parte del mundo, así como de pensadores con los cuales se puede coincidir parcial o totalmente (Guadarrama, 2001, p. 385).

3. Cursivas en el original. 
Para la región resulta decisivo asumir este desafío: «[...] América Latina tendrá que pagar dobles cuotas de sacrificio si no asume a tiempo no solo la actitud de pensar con cabeza propia, sino, lo que es más importante, de actuar» (Guadarrama, 2001, p. 388).

En medio de condiciones tan adversas, el intelectual que quiere seguir siéndolo, y cada vez mejor, que no se abochorna de sus marcados tintes ideológicos, se reúne, escribe, diserta, critica, en cualquier medio que le sea posible y cultiva el más digno humanismo [...] La misión de la intelectualidad comprometida con esas periferias es desarrollar, ante todo, el rasgo principal de todo ejercicio epistémico: pensar con cabeza propia (Guadarrama, 2001, p. 392) .

Para Pablo trabajar en equipo y fomentar el trabajo en equipo y la formación de sus nuevas y nuevos integrantes ha sido y sigue siendo labor irrenunciable. Lo cual compartimos plenamente.

La labor pedagógica forma parte intrínseca del quehacer del filosofar. Carece de sentido dedicarnos a hacerlo y no colaborar en la formación de otras y otros para realizarlo.

Por otra parte, también hemos compartido la fecundidad de movernos por el mundo para poder adquirir una visión y percepción más amplia de la realidad humana.

Quizá por todo esto la dimensión utópica anda siempre dando vueltas entre nuestras reflexiones y quehaceres o, también, por pertenecer a esas generaciones de sesentistas y setentistas como después se les ha denominado, aunque eso solo sería tema de amplias indagaciones. Por ello nos siguen resultando movilizadoras sus expresiones al respecto, como cuando afirmaba: «La utopía no muere, reverdece entre los pies de su sepulturero» (Guadarrama, 1994, p. 103).

Y cuando recalcaba algo que sigue marcando nuestra ruta hoy: «En lugar de filosofías de protesta a los latinoamericanos les hacen más falta filosofías de propuestas» (Guadarrama, 1994, p. 103).

Al tiempo que volvemos a invitar a revisar sus aportes con todo cuidado, solo nos resta felicitar al amigo por su esfuerzo y a seguir admirando su obstinación para avanzar en la ruta trazada. No podemos eludir la responsabilidad de hacer propuestas y avanzar en su concreción.

Cuernavaca, Morelos, México, 15 de mayo de 2014.

4. Cursivas en el original. 


\section{Referencias}

Colectivo de autores (2009). Valores fundacionales de la integración latinoamericana. Santa Clara: Editorial Feijóo Universidad Central de Las Villas.

Hart Dávalos, A. (2008). Prólogo. En P. Guadarrama, Pensamiento filosófico latinoamericano: bumanismo vs. Alienación, Tomo I (p. 23). Caracas, Venezuela: El perro y la rana.

Guadarrama, P. (1979, enero-abril). El análisis marxista-leninista de la historia de la filosofía frente a las tergiversaciones de la historiografía burguesa. Islas. Revista de la Universidad Central de Las Villas. Santa Clara, Cuba, (62), pp. 159-176.

Guadarrama, P. (1983). El problema de la autenticidad de la filosofía latinoamericana. Boletín de información bibliográfica del Departamento de Educación Interna del Comité Central del Partido Comunista de Cuba, (3), pp. 118-142.

Guadarrama, P. (1985). Valoraciones sobre el pensamiento filosófico cubano y latinoamericano. La Habana: Editora Política.

Guadarrama, P. \& Pereliguin, N. (1988). Lo Universal y lo Específico en la Cultura. Bogotá: UNINCCA - Universidad Central de Las Villas Santa Clara, Cuba.

Guadarrama, P. (1990). Marxismo y antimarxismo en América Latina. Bogotá: UNINCCA - Universidad Central de Las Villas Santa Clara, Cuba.

Guadarrama, P. (1994). América Latina: marxismo y postmodernidad. Bogotá: UNINCCA-UNED - Universidad de Las Villas (Santa Clara, Cuba).

Guadarrama, P. \& Rojas, M. (1995). El pensamiento filosófico en Cuba en el siglo XX (1900-1960). «Presentación» Manuel Velázquez Mejía. Toluca: México, UAEM - Universidad Central de Las Villas.

Guadarrama, P. (1995) ¿Qué se incrementa: la alienación o la desalienación en la modernidad? En: C. B. Gutiérrez (editor), El trabajo filosófico boy en el Continente (pp. 1089-1096). Actas del XIII Congreso Interamericano de Filosofía, Bogotá, Colombia. 4 al 9 de julio de 1994.

Guadarrama, P. (2002). El tema de la cultura en el pensamiento latinoamericano. En: E. Montiel \& B. G. De Bosio (Eds.). Pensar la mundialización desde el Sur. IV Corredor de las Ideas (pp. 91-104). Asunción, Paraguay: Unesco -Mercosur - Konrad Adenauer Stiftung - CIDSEP (Universidad Católica). 
Guadarrama, P. (2008). Cultura. En H. E. Biagini \& A. A. Roig (Dir.), Diccionario del pensamiento alternativo (pp. 140-141). Buenos Aires: Biblos.

León del Río, Y. \& Valdés García, F. (2001). Pablo Guadarrama González (1949). En: C. A. Jalif de Bertranou (comp.). Semillas en el tiempo. El latinoamericanismo filosófico contemporáneo. Mendoza, Argentina: EDIUNC.

Rezende de Carvalho, E. (2009). Pensadores da América Latina: o movimento latino-americano de história das idéias. Goiânia, Brasil: Universidade Federal de Goiás. 